\title{
The Problem of Sex Determination in Dinophilus gyrociliatus.
}

By

\author{
Cresswell Shearer, M.A. \\ Clare College, Cambiridge.
}

The group of primitive Annelids Dinophilus comprises some eight or nine species. They are remarkable for the fact that some show a well marked sexual dimorphism, in which the male is rudimentary, without any mouth or digestive tract, while in others the sexes are the same size and exhibit no signs of this dimorphism. The group as a class, therefore, is readily divisible into two subdivisions, in one of which all the species are sexually dimorphic, unpigmented, while in the other they are highly pigmented, a bright red, and are sexually monomorphic. The former may be called the Leucodinophilidae, while the latter may be called the Erythrodinophilidae. The known species, many of which are of doubtful specific value, may be arranged under these two subdivisions, as follows :-

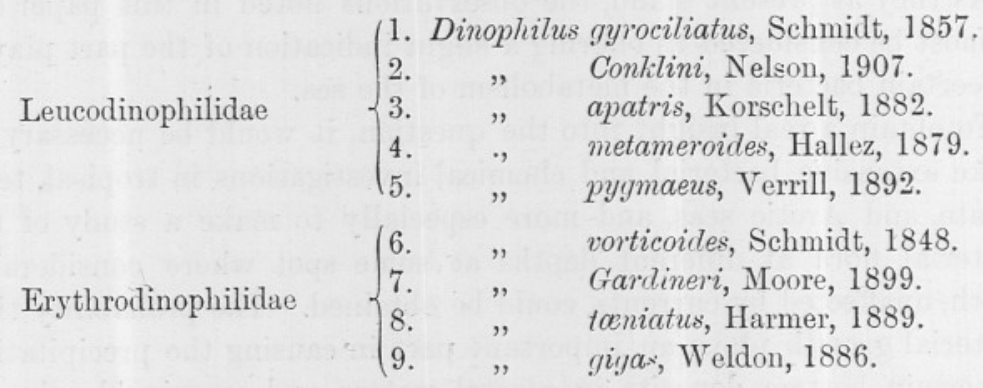

Of the Leucodinophilidae the first three species, D. gyrociliatus, D. Conklini, and D. apatris, are closely related, and are probably one and the same. The form on which the following work has been done is one of these three species, though exactly which of the three I have been unable to decide. I have placed it under the head of $D$. gyrociliatus, as this is the oldest of these names. Figures of the male and female drawn to scale, are shown in Fig. 1. It will be seen that the female is very much larger than the 
male, and that the sexual dimorphism is well marked. It was obtained some three years ago from some sandy material collected in Plymouth

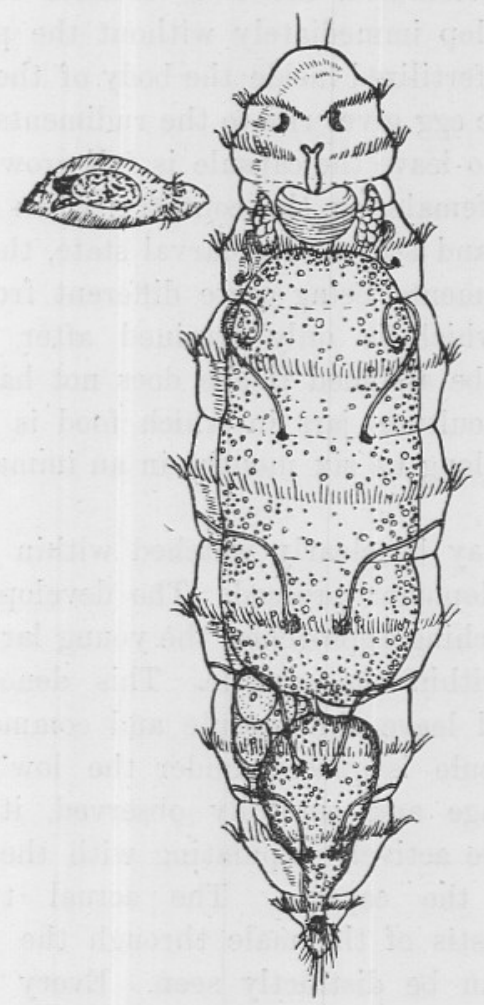

FIG. 1.-Dinophilus gyrociliatus. Rudimentary male and full-grown female. The female shows the broken nature of the ciliated bands in the head region and the solenocyte bearing nephridia.

Sound. I introduced it subsequently into the tanks of the Plymouth Laboratory, where it has since established itself, and breeds.

Korschelt was the first to point out that a marked sexual dimorphism is present in $D$. apatris, where the male is small and rudimentary. $\mathrm{He}$ also observed that the female laid two kinds of eggs together in one capsule. Some of these were almost six times the size of the others, and were destined to give rise to the females, while the small ones gave rise to the rudimentary males. The large female eggs are laid in the proportion of three to one of the small male ones. Here is apparently a clear case in which we get sex determination in the ovary long before fertilization. Korschelt took it for granted that the eggs were only fertilized after being laid. The presence of this species of Dinophilus at Plymouth afforded me the opportunity of thoroughly investigating 
this question again, and of determining the manner of formation of these two kinds of eggs.

As Korschelt has determined, the two varieties of eggs are laid together, but they develop immediately without the presence of the male, and are therefore fertilized inside the body of the female. In a few days the small male egg gives rise to the rudimentary male, which at the time it is ready to leave the capsule is full-grown and sexually mature (Fig. 1). The female, on the contrary, when she leaves the capsule, is very small, and still in the larval state, the ciliation and arrangement of the segments being quite different from that in the full-grown condition, which is only attained after a considerable period, and may never be assumed if she does not happen to obtain proper food. Thus in culture jars in which food is not found, the females will remain as long as six months in an immature condition, and never grow up.

The young worms may be clearly watched within the capsule as segmentation and development proceed. The development is direct, and as the time for hatching approaches, the young larval females are seen to spin round within the capsule. This denotes that they are about to hatch and leave the capsule and commence their free existence. If the capsule is placed under the low power of the microscope at this stage and carefully observed, it will be seen that the little males are actively copulating with the small females at this time within the capsule. The actual transference of the sperm from the testis of the male through the penis into the body of the female can be distinctly seen. Every female as she passes out of the capsule is seen to carry a small mass of sperm, collected under the gut at the junction of stomach and intestine at the point where the ovary will subsequently appear. The rudimentary males seldom or never leave the capsule, dying shortly after the females escape. Examination of any immature free-swimming females, taken from culture dishes at random, always shows that they are all fertilized. If they are carefully fixed and sections cut from them at this stage, it will be seen that the germ cells have not been differentiated, and although a mass of sperm is collected at the point where the ova will subsequently appear, no trace of them can be detected. These only appear at a much later date, when the female has grown considerably in size. They are seen then as a few small refractive cells in the living state, and as small nuclei surrounded with hardly any cytoplasm in the stained condition, beneath the gut and amongst the mass of sperm. Shortly after they appear it is seen that each one is joined by a spermatozoon, the head of which 
has become embedded or attached to its nuclear wall, so that ultimately the nucleus of each primitive ovum is seen to be composed of one part derived from the spermatozoon, and the other part the female portion. These two elements of the nucleus never fuse, but retain their individuality throughout all the öogonial divisions. The double nucleus divides amitotically, each half separately. In the majority of the divisions the male and female portions of the nucleus divide equally, so that a similar quantity of nuclear material, both male and female, gets into each daughter cell. There are probably about forty to fifty öogonial divisions in all. In these the male and female portions of the nucleus divide and move apart simultaneously, the male portion usually dividing first. Now and again, however, the female half of the nucleus seems to divide before the male portion, so that the male portion gets left behind and is shut off entirely in one of the daughter cells. Therefore of the two resulting cells of this division, one has the whole of the male part of the original nucleus and its share of the female portion, while the other has only half the female and no male substance. This appears to be the sex determining factor; for of these two daughter cells, the one that has received the whole of the male element, plus the female element, becomes the female, while that which has received the female portion alone becomes the male. Both these kinds of eggs, once the sex determining division has taken place, grow rapidly. They seem to accomplish this through the power of absorbing and building up into themselves all the other immature egg cells with which they happen to come in contact, and in which the divisions of the two portions of the male and female substance has been equal. The outcome of this process is that the male egg is not fertilized, while the female egg is. It is, however, impossible to speak in the strict sense of the word of the male egg as unfertilized, as it has been directly under the influence of the sperm in all the early öogonial divisions previous to the sex determining one. For all the primitive germ cells are joined in the first place by a spermatozoon, irrespective of the fact that only some of these will give rise to ova later, and that the majority will be only nurse cells. It is only in the late stages, shortly before the female egg is laid, that the two portions of the nucleus, the male and female actually fuse beyond recognition. As the two kinds of eggs, male and female, are not found in a simple ratio, but in the proportion of three or two, to one male, it is probable that some other division takes place in the case of the female egg. I have been unable to decide this point so far, from my sections.

I have made a careful study of the maturation divisions, and as Kor* 
schelt has determined in $D$. apatris, there are two polar bodies given off by both kinds of eggs, the first polar body in turn dividing after it has been given off. There are twenty somatic chromosomes. In both eggs there is a regular reduction in the first maturation division, ten dumbbell shaped chromosomes going out and ten remaining in the egg. In the female egg, however, this process is somewhat different from that in the male, as there seems to be something similar to a synapsis stage in the former which is missed out in the latter. In both eggs after the extrusion of the first polar body, the ten chromosomes remaining in the egg divide, bringing back the number to twenty again. In the second polar body, in the male egg, apparently twenty or eighteen chromosomes go out and the same number remain in the egg. The second maturation division in the female egg, I have been unable to obtain satisfactorily in sections so far, and it may prove that the second polar body in this egg is simply derived from division of the first, and that only one polar body is actually given off by the female egg. In the first and second segmentation divisions in both eggs there are apparently twenty chromosomes. It is, however, very difficult to make out their number in the male egg very accurately on account of their small size, there are at least eighteen or more, and probably twenty, as in the female egg.

The details of the maturation divisions I wish to reserve for my full paper on the subject, shortly appearing in the Quarterly Journal of Microscopical Science. 